\title{
Global Inc: an experiment across time and space
}

\author{
B. C. Glasson
}

School of Information Systems, Curtin University, GPO Box U1987 Perth 6001, West Australia, Phone +619 351 7685; Fax +619 351 3076; Email Glasson@BA1.curtin.edu.au

D. R. Vogel

Department of MIS, 430EE McClelland Hall, University of Arizona, Tucson, AZ 85721 USA, Phone + 520621 4475;

Fax + 520621 2433; Email Vogel@bpa.arizona.edu P. W. G. Bots

Department of Systems Engineering and Policy Analysis, Delft University of Technology, PO Box 5015, NL-2600 GA Delft,

The Netherlands, Phone +31 15782 948; Fax +31 15783 429;

Email Bots@sepa.tudelft.nl

\begin{abstract}
Recent and rapid developments in electronic commerce enabled global trading have raised many questions about future office work. In the light of these questions IFIP WG 8.4 has organised series of events which will culminate with the running of a globally distributed working conference in September 1997. The September 1997 conference will focus on "Global Inc". Global Inc is a mythical organisation. Global Inc in its first incarnation will run for some 50 hours around the clock in three countries to simulate the 24 hour-a-day operations of a globally distributed organisation. It will serve three purposes. It will provide a forum through which researchers and developers can report and discuss IOF research outcomes. It will allow participants to live the experience of working in a globally distributed, 24 hour-a-day "organisation". And it will provide a "laboratory" through which to conduct experiments in future office technologies, processes or work practices.
\end{abstract}

\section{Key words}

Electronic Commerce, Future Office, Global Trade, International Business, Distributed Teamwork, Inter-organisational Systems, Computing and Communications Technology 


\section{INTRODUCTION}

This papers discusses the third in a series of related research activities focussing on the international office of the future (IOF). This trilogy of IOF events has been devised and managed by IFIP WG 8.4. The International Federation for Information Processing (IFIP) exists to encourage and assist in the development, exploitation and application of information technology for all people. It operates through a number of technical committees (TC's). The TC's in turn comprise a number of working groups (WGs). WG 8.4 has the responsibility within IFIP for promoting research, development, application, education and information dissemination in the field of office systems.

In 1993, WG 8.4 forecast the rapid development and expansion of electronic commerce (Vogel 1993). The maturation of network technology and the commercial interest in the internet seemed to be providing the supply-side technology push for a new era of electronic commerce (eg. (Piel 1991)). At the same time the forces of globalisation seemed to be providing the demand-side pull (eg. (Tapscott 1993)). These supply and demand forces foreshadowed a new era of computing and telecommunications enabled international business - an era of global business based on global information technology bringing with it a number of opportunities and challenges (eg. (Ives 1991)). Hence the question - what would be the international office of the future (IOF)? This overall question spawned many sub-questions. Will the future office be a place or a space? Are the technologies sufficiently mature to support effective inter-organisational systems - and if not, what development work needs to be done, and if so, how best do we diffuse them? How do we manage inter-group synchronous and asynchronous communication? How do we manage multi-cultural and multi-disciplinary teams? How do we change business processes to adapt to, or capitalise on, a global trading environment? What would be the worker, work-place, organisational and even societal outcomes of the IOF? And these broad questions in turn generated many more detailed ones. As a consequence WG 8.4 agreed on a plan of research focussing on the IOF which culminates with a living experiment called "Global Inc".

\section{GLOBAL INC}

\section{Distributed Working Conference}

Global Inc is a mythical organisation. It is a concept rather than an entity. Some would call it a virtual organisation. Its line of business is IOF research, development, application, education and information dissemination. Its reason for being is to enable researchers and developers with an interest in any aspect of the IOF to work for a short while in a globally distributed organisation. In September 1997 Global Inc will run as a globally distributed working conference around the clock in three geographic regions over a period of two consecutive days. The theme of the working conference is "The International Office of the Future: Working Apart Together". Each region will take responsibility for a particular conference track. Each track will probably comprise two sessions. Each session will be made up of presentations, panels, birds-of-a-feather sessions or experiments. The Asia/Pacific region will run the organisational aspects track. The European region will run the business processes track. And the Americas region will run the technology track. Interested researchers and developers will be invited to participate in the work of Global Inc by physically attending at one of the regional centres. It is assumed participants will either choose the region running the track which is of most interest to them or the region that is closest. All the regions will be linked by technology of various levels of sophistication to facilitate information exchange and to enable collaboration. 


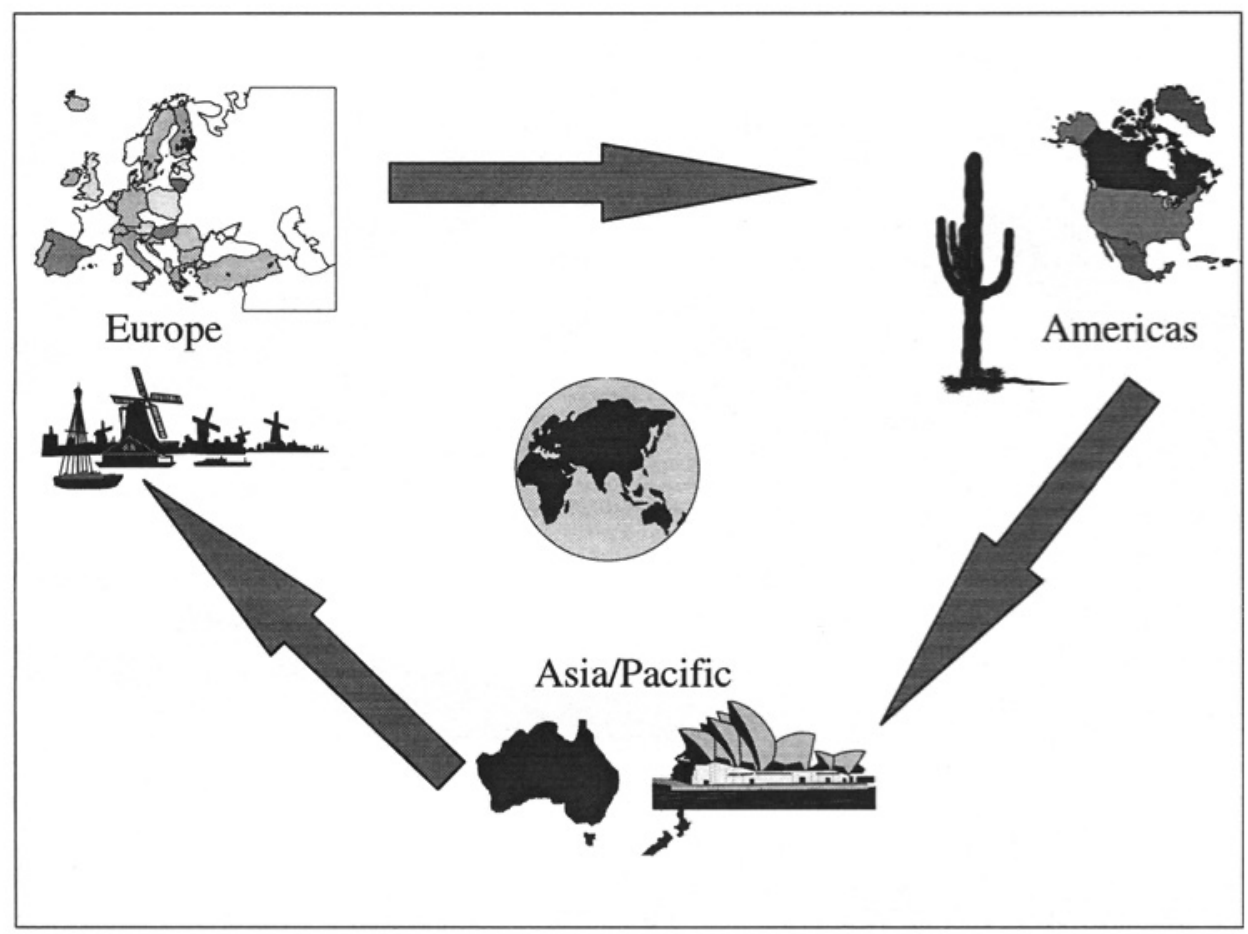

Figure 1 Global inc Work Flow

At any one time each region will either be "in session", "on-line" or "off-line". When "in session" the region will be holding same-time, same-place, face-to-face activities for its local participants. It will also be responsible for distributing its work to the other two sites. When "on- line", the region will be linked to the "in-session" region to allow for same-time but different-place interaction. When "offline" a region will not be engaged in Global Inc work. Work done at either of the "in-session" or "on-line" regions will need to be accessed by the "off-line" region later in a different-time, differentplace mode of working.

\section{Around the Clock}

Global Inc will commence its Asian Pacific operations al (say) 1900 hours local time on Thursday September 251997 at Curtin University in Perth, Western Australia. It will commence its European operations some 8 hours later in The Netherlands at the University of Delft. And it will commence it Americas operations at the University of Arizona in Tucson, USA approximately 8 hours after that. Once operational it will run on a 24 hour basis for some 50 hours (ie until 1700 hours local time in Tucson Arizona USA, Saturday, September 27 1996). The "baton" would start in Perth. The Asia/Pacific region would close its first working day with a "keynote" address or panel which would be sharcd by the European centre via video link. At the conclusion of the Asia/Pacific keynote address the "baton" would pass to Delft. Similarly the European centre's closing session would be shared with the Americas and the America's closing session would be shared with Asia/Pacific. The 
Table 1 Prototype Work Schedule

\begin{tabular}{|c|c|c|c|c|c|c|}
\hline $\begin{array}{l}\text { Project } \\
\text { Time }\end{array}$ & \multicolumn{6}{|c|}{$\begin{array}{l}\text { Regional Centres Day, Approximate Local Time and Activity } \\
\text { Approximate times and } 8 \text { hour blocks are used here for illustration purposes only. The } \\
\text { "baton" holder is shown in bold. The baton holder region will be "in session". The two other } \\
\text { regions will either be "on-line" (ie participating in the active regions session synchronously } \\
\text { via a link) or "off-line" (ie will have access to outputs from the active region's session } \\
\text { asynchronously). Shading indicates a two-way video link }\end{array}$} \\
\hline \multirow[t]{2}{*}{$\begin{array}{l}\text { Start Time } \\
\text { minus "n" }\end{array}$} & \multicolumn{6}{|c|}{$\begin{array}{l}\text { All regions could be involved in some pre-conference collaborative research project set-up } \\
\text { activities }\end{array}$} \\
\hline & \multicolumn{2}{|c|}{ Perth } & \multicolumn{2}{|c|}{ Delft } & \multicolumn{2}{|l|}{ Tucson } \\
\hline $\begin{array}{l}\text { Evening } \\
\text { before local } \\
\text { Start Time }\end{array}$ & Local Welcome & Thu 2000 & Local Welcome & Thu 2000 & Local Wel & Thu 2000 \\
\hline $\begin{array}{l}\text { Start Time } \\
01 \mathrm{Hrs}\end{array}$ & Session 1 & Fri 0800 & & & & \\
\hline $08 \mathrm{Hrs}$ & Keynote & Fri 1600 & On-line & Fri 0800 & & \\
\hline $10 \mathrm{Hrs}$ & On-line & Fri 1800 & Session 2 & Fri 1000 & & \\
\hline $16 \mathrm{Hrs}$ & Off-line & & Keynote & Fri 1600 & On-line & Fri 0800 \\
\hline $18 \mathrm{Hrs}$ & Off-line & & On-line & Fri 1800 & Session 3 & Fri 1000 \\
\hline $24 \mathrm{Hrs}$ & On-line & Sat 0800 & Off-line & & Keynote & Fri 1600 \\
\hline $26 \mathrm{Hrs}$ & Session 4 & Sat 1000 & Off-line & & On-line & Fri 1800 \\
\hline $32 \mathrm{Hrs}$ & Keynote & Sat 1600 & On-line & Sat 0800 & Off-line & \\
\hline $34 \mathrm{Hrs}$ & On-line & Sat 1800 & Session 5 & Sat 1000 & Off-line & \\
\hline $40 \mathrm{Hrs}$ & Off-line & & Keynote & Sat 1600 & On-line & Sat 0800 \\
\hline $42 \mathrm{Hrs}$ & Off-line & & On-line & Sat 1800 & Session 6 & Sat 1000 \\
\hline $48 \mathrm{Hrs}$ & $\begin{array}{l}\text { On-line } \\
\text { Over breakfast }\end{array}$ & Sun 0600 & $\begin{array}{l}\text { On-line } \\
\text { After dinner }\end{array}$ & Sat 2400 & $\begin{array}{l}\text { Closure } \\
\text { Followed } t\end{array}$ & $\begin{array}{l}\text { Sat } 1600 \\
\text { ner }\end{array}$ \\
\hline $50 \mathrm{Hrs}$ & \multicolumn{6}{|l|}{ End of event } \\
\hline $\begin{array}{l}\text { End Time } \\
\text { plus " } n "\end{array}$ & \multicolumn{6}{|c|}{ Write-up of conference related collaborative research activity } \\
\hline
\end{tabular}


"baton" being passed to the next region after the baton-holder's closing session for the day (see Figure 1, Global Inc Work Flow above).

One possible arrangement of work is shown in Table 1, Prototype Work Schedule above. We stress possible because one of the aims of this conference is to set the level of ambition for the 1997 event and to agree the work arrangement (see Conference Format below).

\section{Format}

Global Inc will run as a three track working conference with a difference. There will be the usual submissions, panels, and birds-of-feather sessions. What will be different is the time and space dimension. Global Inc will run for 24 hours a day across three continents. This will provide an opportunity for participants to "walk the talk" and experience around the clock work. It will also provide the opportunity for experimentation given rich variety of work modes being used.

Participants may work in one of several modes. The variables determining the mode of work being place, time, face-to-face, interaction type, and action type (see Table 2, Some Work Type Variable Alternatives below). An important coordinating resource will be the Global Inc "Project Clock". The local time at each regional centre will need to be linked to the "Project Time". As the project time advances, the possible work types the participants in each region might experience will change.

Table 2 Some Work Type Variable Alternatives

\begin{tabular}{|l|l|l|}
\hline Variable & Alternative & Explanation \\
\hline Place & Same & Participants are at the same location. \\
\hline & Different & Participants are at a different location \\
\hline Time & Same & $\begin{array}{l}\text { Participants are working at the same project time - but the local } \\
\text { time may well be different }\end{array}$ \\
\hline & Different & Participants are working at different project times \\
\hline & Yes & Participants have eye contact \\
\hline Interactive & No & Participants do not have eye contact \\
\hline & Yes & Participants can interact in real time (Full Duplex) \\
\hline Action Type & Initiates & Participants must communicate in turn (Half Duplex) \\
\hline & This region initiates the work activity \\
\hline & Reacts & This region responds to work initiated by the active region \\
\hline & Observes & This region observes the work outcomes of others \\
\hline
\end{tabular}

\section{Experimentation}

WG 8.4 sees the Global Inc working conference as making a contribution to the field in three ways.

First, the subject matter is timely and important. The concept of an "information superhighway" changing the way we do business and impacting the way we live is as topical as it is potentially significant. Therefore the contributions made through the traditional working conference submissions will add to our knowledge of the field.

Second, Global Inc will enable those of us interested in the IOF to truly experience working in an around the clock "organisation". As this mode of work is novel for most of us, Global Inc will be for many a unique experience.

Third, it will provide a living laboratory for experimentation. In calling for participation in the 1997 Global Inc working conference, WG 8.4 will be particularly interested in receiving submissions proposing experiments that can be conducted during the Global Inc conference. They may be experiments involving joint authoring or collaborative writing; they may be short studies requiring 
Delphi; they may be observations of one or other of the conference activities (eg a distributed panel); or they may propose short laboratory type experiments with control groups and experimental groups using different modes of work ( eg a six team management game with two teams made up of participants from a single region, two teams made up of participants from two regions, and two teams with participants from all three regions). Conference participants would be encouraged to take part in these experiments as part of the Global Inc experience.

\section{TRILOGY}

The 1997 Global Inc working conference will be the culmination of three WG 8.4 activities. The two earlier sets of activities have, or will have, an important part in shaping the eventual Global Inc event. One set of activity took place in September 1994. The second is the subject of these proceedings.

The focus of the 1994 activity was "The International Office of the Future: A Problem Analysis". It was an attempt to define the opportunities and challenges facing any organisation contemplating engaging in computing and telecommunications enabled global business activities. Those opportunities and challenges were surfaced in a series of workshops. The outcome gave some insight into the issues that would need to be addressed in running Global Inc (Bots 1995).

The second activity is the subject of these proceedings. This working conference on "The International Office of the Future: Design Options and Solution Strategies" has brought together researchers and practitioners with an interest in proposing, testing or discussing design options and solution strategies for dealing with key technological, business process and work practice issues of the IOF. The conference has two aims. First it aims to make a contribution to the field through the published submissions. The second aim is to develop socio-technical infrastructure requirements for Global Inc. The first aim will be achieved through the publication and dissemination of these proceedings. The 30 full submissions or extended abstracts address a range of IOF issues and will make a contribution to the field in their own right. How we intend to achieve the second aim needs some explanation.

The focus of this conference is Global Inc. Our secondary aim for this 1996 event is to develop a set of socio-technical infrastructure specifications for WG 8.4's 1997 global conference which we are referring to as the Global Inc Design. These specifications will guide the organising and program committee members as they bring Global Inc into being. In this sense this IOF Design Option and Solutions Strategies event here at the University of Arizona will truly be a working conference. These specifications will be developed over the course of the conference by the participants working in designated teams.

The conference will begin with two plenary sessions. In the opening plenary session we will attempt to develop the Global Inc "vision". The process will use stakeholder input to develop a shared vision of Global Inc which will serve to give the various working activities of the conference a focus. The second plenary session involves presentations of three different distributed environments three views that might give insights into how the Global Inc socio-technical infrastructure might be developed.

These opening plenary sessions will be followed by a number of parallel paper and panel presentations which will run from the afternoon of the first day of the conference until mid-afternoon 
of the second. Each paper or panel relates directly or indirectly to an aspect of Global Inc that will need to be considered by the Global Inc design teams. Topics groupings include organisational aspects; technology aspects; culture; group support; international business; technology transfer, diffusion and adoption; video and computer conferencing; IOF work and workers; team facilitation; office architectures; and an array of IOF research issues.

Mid-way through the second day, participants will be arranged into multi-disciplinary Global Inc design teams. The teams will first meet over a working lunch to decide their modus operandi. The last session of that second day will be given over to Global Inc design workshops. Each team will be asked to develop a suggested design for Global Inc that is in line with the agreed vision based on the design options and solutions strategies raised during the conference to date. In the morning of the final day of the conference these "designs" will be presented in plenary session. These designs, separately or collectively will be used by the 1997 conference committee to develop Global Inc. And while the focus of the designs will be Global Inc, this will not be the exclusive focus of the conference. We anticipate that aspects of these designs will have general application.

The conference will close with a plenary panel which will explore IOF futures. The panel will look beyond Global Inc both in terms of issues and time horizon.

\section{CONCLUSION}

Global Inc is an attempt by WG 8.4 to replicate the workings of a globally distributed organisation operating around the clock. The success or otherwise of Global Inc will depend to a large part on the insight, enthusiasm and input of those participating in this years IOF conference here at the University of Arizona. We see Global Inc as great opportunity. We hope you do as well.

\section{REFERENCES}

Bots, P.W.G., Glasson, B.C and Vogel, D.R (eds) (1995) International Office of the Future: A

Problem Analysis, Technische Betuurskunde, Delft University, Delft, The Netherlands

Ives, B. and Jarvenpaa, S.L. Applications of Global Information Technology: Key Issues for Management, MIS Quarterly March 1991

Piel, J. (Ed) (1991) Communications, Computers and Networks, Scientific America Special Issue Vol 265 No 3, September 1991

Tapscott, D. and Caston, A. Paradigm Shift: the New Promise of Information Technology, McGraw Hill NY, 1993.

Vogel, D.R., Marshall, P.H., Glasson,B.C. and Verrijn-Stuart, A.A. (Eds) (1993) Local Area

Network Applications: Leveraging the LAN, IFIP Transactions A-31 North-Holland, Amsterdam, 1993 


\section{BIOGRAPHY}

Bernard Glasson is chairman of IFIP TC8 and program chair for this conference. Doug Vogel is chairman of IFIP WG 8.4 and the organising chair of this conference. Pieter Bots is vice chair of IFIP WG 8.4. Glasson, Vogel and Bots jointly developed the IOF trilogy concept and are taking various active roles in its implementation. 